\title{
Investigating Processes of Nanocrystal Formation and Transformation via Liquid Cell TEM
}

\author{
Michael H. Nielsen, ${ }^{1}$ Dongsheng Li, ${ }^{2}$ Hengzhong Zhang, ${ }^{3}$ Shaul Aloni, ${ }^{4}$ T. Yong-Jin Han, ${ }^{5}$ \\ Cathrine Frandsen, ${ }^{6}$ Jong Seto, ${ }^{7,8}$ Jillian F. Banfield, ${ }^{3}$ Helmut Cölfen, ${ }^{7}$ and James J. De Yoreo ${ }^{2, *}$ \\ ${ }^{1}$ Department of Materials Science and Engineering, University of California, Berkeley, Berkeley, CA 94720, USA \\ ${ }^{2}$ Physical Sciences Division, Pacific Northwest National Laboratory, Richland, WA 99352, USA \\ ${ }^{3}$ Department of Earth and Planetary Science, University of California, Berkeley, CA 94720, USA \\ ${ }^{4}$ Molecular Foundry, Lawrence Berkeley National Laboratory, Berkeley, CA 94720, USA \\ ${ }^{5}$ Physical Sciences Directorate, Lawrence Livermore National Laboratory, Livermore, CA 94551, USA \\ ${ }^{6}$ Department of Physics, Technical University of Denmark, 2800 Kongens Lyngby, Denmark \\ ${ }^{7}$ Department of Physical Chemistry, University of Konstanz, D-78457 Konstanz, Germany \\ ${ }^{8}$ Department of Chemistry, École Normale Supérieure, Paris 75005, France
}

\begin{abstract}
Recent ex situ observations of crystallization in both natural and synthetic systems indicate that the classical models of nucleation and growth are inaccurate. However, in situ observations that can provide direct evidence for alternative models have been lacking due to the limited temporal and spatial resolution of experimental techniques that can observe dynamic processes in a bulk solution. Here we report results from liquid cell transmission electron microscopy studies of nucleation and growth of $\mathrm{Au}, \mathrm{CaCO}_{3}$, and iron oxide nanoparticles. We show how these in situ data can be used to obtain direct evidence for the mechanisms underlying nanoparticle crystallization as well as dynamic information that provide constraints on important energetic parameters not available through ex situ methods.
\end{abstract}

Key words: liquid cell TEM, nucleation, oriented attachment, crystal growth

\section{INTRODUCTION}

Nucleation and growth of inorganic crystals from solutions occurs throughout geochemical, biological, and synthetic systems. Until recently, classical nucleation theory (CNT) first developed by Gibbs (Gibbs, 1876, 1878) and the terraceledge-kink model put forth by Burton Cabrera and Frank (BCF) (Burton et al., 1951) were widely accepted as accurate descriptions of nucleation and growth, respectively. However, in the last decade a number of observations have led to alternative views of both processes that call into question the basic tenets of the models (De Yoreo, 2013).

According to CNT (Gibbs, 1876, 1878; Kashchiev, 1999), nucleation occurs through density fluctuations that give rise to unstable clusters, which occasionally overcome a free energy barrier through ion-by-ion addition to produce a stable seed crystal. Within this classical picture, when an electrolyte solution is undersaturated all clusters are unstable relative to the free ions, and cluster concentration falls off exponentially with size. Moreover, although the formation of metastable phases may be kinetically favorable, the thermodynamically stable phases of both the nucleus and bulk crystal are assumed to be the same. However, a number of studies have reported the existence of multi-ion complexes of order $1 \mathrm{~nm}$ or more in diameter that are present before nucleation and, at least in some cases, are

Received March 10, 2013; accepted January 24, 2014

${ }^{*}$ Corresponding author. james.deyoreo@pnnl.gov believed to be stable constituents of the solution even in an undersaturated solution (Gebauer et al., 2008; Pouget et al., 2009; Dey et al., 2010; Gebauer \& Cölfen, 2011; Habraken et al., 2013). Birth of the solid phase in these systems then occurs through aggregation of these prenucleation clusters to form nanoparticles of a stable precursor phase that is often poorly ordered or amorphous and later transforms into the crystalline phase (Gebauer et al., 2008; Pouget et al., 2009; Dey et al., 2010; Gebauer \& Cölfen, 2011; van Driessche et al., 2012; Habraken et al., 2013; Baumgartner et al., 2013). The barrier to nucleation via this route is thought to be minor and thus circumvents the classical nucleation process. Moreover, other experimental and computational studies of the calcium carbonate system suggested that formation of the first precipitate is not a product of nucleation at all, but rather results from spinodal decomposition of the solution into two liquid phases, one of which is a solute-rich dense liquid phase (Faatz et al., 2004; Wolf et al., 2008; Bewernitz et al., 2012; Wallace et al., 2013). The solid phase then forms within this dense liquid phase.

According to BCF theory (Burton et al., 1951), once nucleation has occurred, crystal growth proceeds through atomic additions to kink sites at step edges produced either at screw dislocations or, at sufficiently high supersaturation, by nucleation of two-dimensional islands. In contrast, many studies have now provided compelling evidence for growth via aggregation and coalescence of nanoparticles in 
biomineral (Politi et al., 2004; Killian et al., 2009), biomimetic (Cölfen \& Antonietti, 2005, 2008), environmental (Banfield et al., 2000; Penn et al., 2001; Cölfen \& Antonietti, 2008), and synthetic systems (Penn \& Banfield, 1998a, 1998b; Yadong \& Alivisatos, 2005; Cho et al., 2005; Zhang et al., 2010). The resulting crystals often exhibit complex forms ranging from quasi-one dimensional chains to $3 \mathrm{D}$ hierarchical and self-similar superstructures (Xu et al., 2008). Yet the final structure typically diffracts as a single crystal (Mann, 2001; Cölfen \& Antonietti, 2008), implying that either the primary particles aligned during the attachment process (Penn \& Banfield, 1998a, 1998b; Banfield et al., 2000; Cho et al., 2005) or through recrystallization via dislocation and grain-boundary migration after attachment (Hackney et al., 1986; Passchier \& Trouw, 1998).

Until the advent of liquid cell transmission electron microscopy (TEM), the primary evidence for these processes came from ex situ TEM observations combined, in some cases, with bulk measurements of solution chemistry via titration and particle size distributions via analytical ultracentrifugation. Direct observations of the nucleation process or the post-nucleation fate of primary particles simply were not possible. Liquid cell TEM has removed that limitation (Radisic et al., 2006a, 2006b). Recently, Liao et al. (2012) and $\mathrm{Li}$ et al. (2012) reported direct observation of oriented nanoparticle attachment (OA) in both metal and oxide systems and Nielsen et al. (2012) reported direct observation of $\mathrm{CaCO}_{3}$ nucleation on gold electrodes. Here we use a number of systems to illustrate the power of this method for discriminating between mechanisms at work during the formation of inorganic crystals. While we do provide quantitative analyses of certain phenomena, the intent of this paper is to provide a qualitative overview that shows how liquid cell TEM can be used to explore a number of processes in nucleation and crystal growth that are currently the subjects of intense study within the geochemical, biomineral and crystal growth communities.

\section{Materials and Methods}

\section{TEM Liquid Cell Fabrication and Assembly}

Our cell design is based on that of Williamson et al. (2003) who used fluid cell TEM to quantitatively study the nucleation and growth of electrodeposited $\mathrm{Cu}$ islands on $\mathrm{Au}$ electrodes (Williamson et al., 2003; Radisic et al., 2006a, 2006b) and is described in detail elsewhere (Li et al., 2012; Nielsen et al., 2012). The cell is composed of two $300 \mu \mathrm{m}$ thick silicon wafers with $100 \mathrm{~nm}$ thick silicon nitride membranes coating both sides of each wafer. The silicon and nitride is etched away to produce nitride membranes that constitute electrontransparent windows either $50 \times 100 \mu \mathrm{m}$ or $50 \times 50 \mu \mathrm{m}$ to $100 \times 100 \mu \mathrm{m}$ depending on the silicon etching time, as well as solution reservoirs to either side of the imaging area. On the lower wafer a spacer layer of silicon nitride is deposited to create the gap to support a fluid layer of an appropriate thickness. This spacer layer can be tailored to the experiment; to date our cells have been fabricated with spacer thicknesses ranging between 200 and $500 \mathrm{~nm}$. Due to bending of the silicon nitride membranes during assembly and operation, the actual thickness of the liquid layer between the windows can be as small as zero, so that no sample is present in the imaging area, to a couple of microns. Thicknesses have been estimated from the size of the particles grown in between the silicon nitride membranes or by measuring the change in the sample height in the $z$ direction when focusing on particles attached on the upper and lower membranes, respectively.

The two wafers are glued together by drawing a small bead of epoxy (M-Bond 610) around the outer edges of the aligned wafers and curing on a hot plate, ramping the temperature from room temperature to $120^{\circ} \mathrm{C}$ over the course of an hour. Two silicon towers that act as solution reservoirs are glued to the upper wafer using the same epoxy. The vast bulk of the fluid cell's reaction volume (total volume is $1-2 \mu \mathrm{L}$, depending on specific geometry) resides in these solution reservoirs, with much $<1 \%$ of the total volume expected in the thin layer between the silicon wafers. When the cell is assembled to this point, solution is injected into one of the reservoirs, where it is drawn through the cell via capillary action. The second reservoir is then filled with solution. Silicon or glass caps are placed over the reservoir openings and sealed to the towers using a UV-curable epoxy (Norland Opticure 63). This procedure results in a hermetically sealed fluid cell that is vacuum compatible with the TEM.

\section{Solution Preparation}

The gold solution was made by mixing $0.5 \mathrm{~mL}$ of a $0.01 \mathrm{M}$ Na-citrate solution and $0.5 \mathrm{~mL}$ of $0.01 \mathrm{M} \mathrm{HAuCl}_{4}$ solution to $18 \mathrm{~mL}$ of DI water. Freshly prepared $\mathrm{NaBH}_{4}$ solution $(0.3 \mathrm{~mL}$ of $0.01 \mathrm{M}$ ) was added to Au-citrate solution to form the gold nanoparticles. The solutions used in these experiments had aged at room temperature for a period of less than a month before use.

Iron (III) chloride (99\%, Aldrich) and potassium dihydrogen phosphate (98\%, Aldrich) from Sigma Aldrich (St. Louis, MO, USA) were used as received. Iron oxide particle synthesis was achieved by mixing $\mathrm{FeCl}_{3}$ and $\mathrm{KH}_{2} \mathrm{PO}_{4}$ solutions to produce a working solution with $20 \mathrm{mM} \mathrm{Fe}{ }^{3+}$ and $0.45 \mathrm{mM} \mathrm{K}^{+}$at $\mathrm{pH} 2.05$ to 2.08 . For in situ experiments, a few microliters of the $\mathrm{FeCl}_{3}-\mathrm{KH}_{2} \mathrm{PO}_{4}$ solution were loaded into the liquid cell, which was sealed and placed into the microscope. Rod-like akaganeite nanoparticles and spindleshaped hematite nanoparticles were produced in ex situ reactions with this solution at $100-150^{\circ} \mathrm{C}$ for $0.5-48 \mathrm{~h}$ by a hydrothermal method in sealed $23 \mathrm{~mL}$ Teflon-lined autoclaves.

Calcium carbonate solutions were prepared by mixing equal volumes of a $20 \mathrm{mM}$ carbonate buffer (mixture of $\mathrm{Na}_{2} \mathrm{CO}_{3}$ and $\mathrm{NaHCO}_{3}$ ) and a solution of $20 \mathrm{mM} \mathrm{CaCl}_{2}$ with $2 \mu \mathrm{M}$ of the sea urchin spicule matrix protein SM50. As the SM50 was expected to stabilize the amorphous $\mathrm{CaCO}_{3}$ 
phase indefinitely, this solution was allowed to sit at room temperature for months before use.

\section{TEM Operation}

The cell described above was used in conjunction with a custom-built TEM stage (Hummingbird Scientific, Lacey, WA, USA) designed to work with JEOL microscopes. Two microscopes were used for the data collected and reported herein: a LaB6 JEOL JEM-3010 operated at $300 \mathrm{kV}$ and a field emission JEOL JEM-2100F operated at $200 \mathrm{kV}$. Video data was collected using the VirtualDub software to either directly capture data from the camera (JEM-3010) or collect cropped screenshots of the live view in Digital Micrograph (JEM-2100F). Image acquisition times ranged from 0.05 to $0.25 \mathrm{~s}$ per image and the image size was either $1001 \pm 1 \times 666 \pm 1$ pixels (JEM-2100F) or $480 \times 480$ pixels (JEM-3010).

\section{Results}

\section{Nucleation of Au Nanoparticles}

Numerous groups have investigated various aspects of gold nanoparticle growth and motion (Chen et al., 2013; Jungjohann et al., 2013). Here we look at the initial nucleation of $\mathrm{Au}$ nanoparticles. Figure 1 and Supplementary Movie 1 show the process of gold nanoparticle formation from a gold chloride solution containing citric acid as a capping agent. While numerous successful particle formation events are

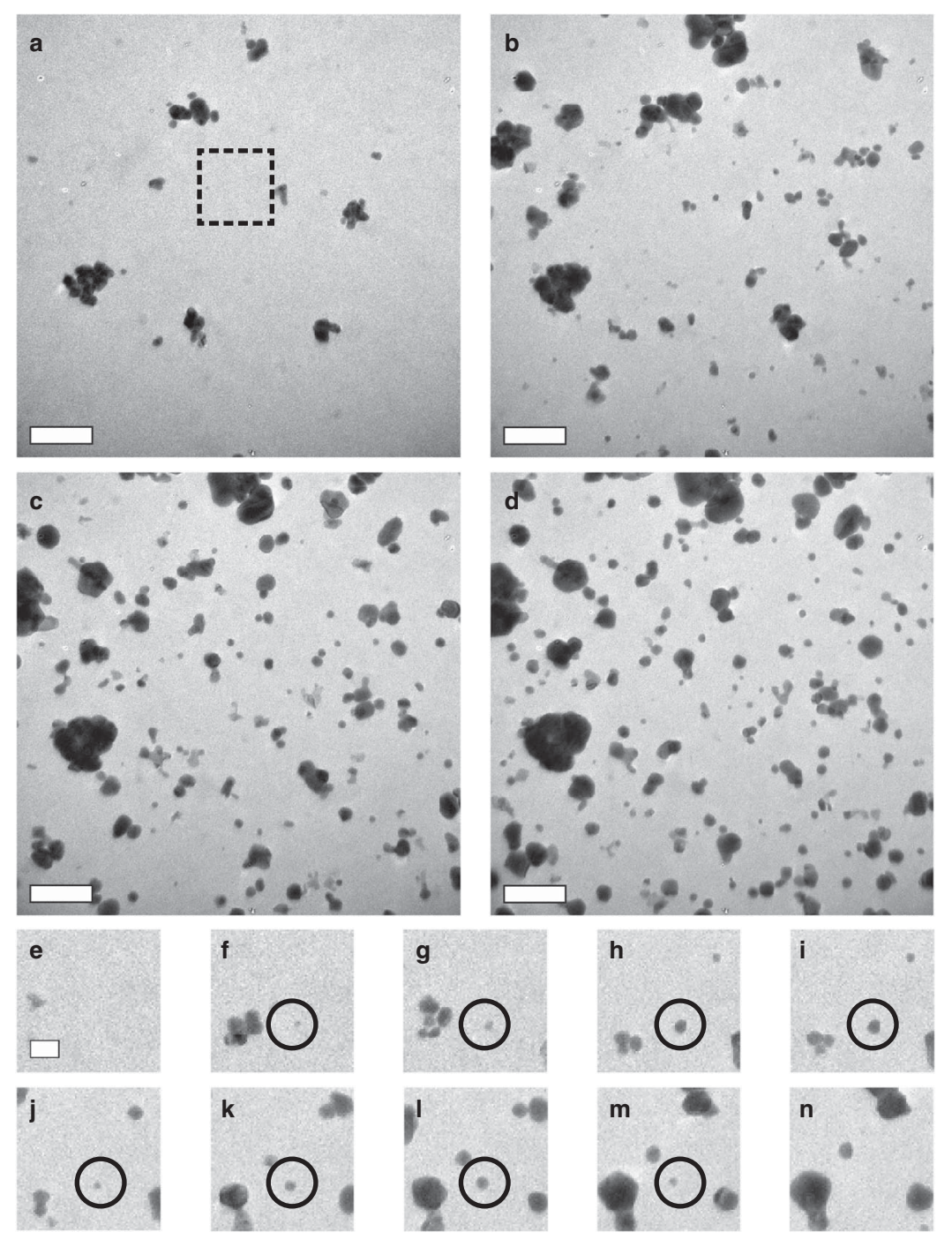

Figure 1. Nucleation of $\mathrm{Au}$ nanoparticles. a-d: Sequence of liquid cell transmission electron microscopy (TEM) images showing the nucleation of $\mathrm{Au}$ nanoparticles from a gold chloride solution containing citrate as a capping agent. As seen in the example highlighted by the circle in $(\mathbf{e}-\mathbf{n})$, which were taken from the region delineated by the rectangular box in (a), many of the nascent nuclei fail to reach the point of spontaneous growth and instead fluctuate in size until they disappear. This behavior demonstrates that particle formation results from unstable fluctuations, the hallmark of classical nucleation. Times in seconds: (a) 0.0, (b) 34.0, (c) 68.1, (d) 103.2, (e) 2.1, (f) 8.0, (g) 16.4, (h) 34.9, (i) 36.6, (j) 44.8, (k) 60.5, (l) 73.1, (m) 93.3, and (n) 103.2. Scale bars: (a-d) $500 \mathrm{~nm},(\mathbf{e}-\mathbf{n}) 200 \mathrm{~nm}$ (also see Supplementary Movie 1). 
observed, there are many instances in which a gold particle begins to form, fluctuates in size, and eventually dissolves away rather than growing into a stable crystal. These fluctuations demonstrate that gold nanoparticles form from solution via a true nucleation process in which sufficiently large density fluctuations are required to take the system over a free-energy barrier and justify a description of the system in terms of the classical rate equation (De Yoreo \& Vekilov, 2003):

$$
J=A e^{E_{\mathrm{A}} / k T} e^{\Delta g_{c} / k T},
$$

where $J$ is the nucleation rate per volume, $k$ is Boltzmann's constant, $T$ is the temperature, $E_{\mathrm{A}}$ is the activation energy associated with the atomic processes such as desolvation and attachment that must occur to form the nucleus, and $\Delta g_{c}$ is the free energy change required to create a critical-size particle relative to that of the free ions. [Without the second barrier, equation (1) would simply describe a chemical reaction that proceeds at a rate fixed by the kinetic barriers to the atomic scale processes.] This result shows that, whether or not multi-ion clusters-stable or unstable-below the resolution of the measurement contribute to formation of the super-critical nuclei, the process exhibits the characteristic feature of classical nucleation.

\section{Supplementary Movie 1}

Supplementary Movie 1 can be found online. Please visit journals.cambridge.org/jid_MAM.

In the classical model, the barrier results from the competition, in the growing particle, between the decreasing bulk free energy and the increasing surface free energy. Defining the supersaturation as $\sigma$ and the surface free energy
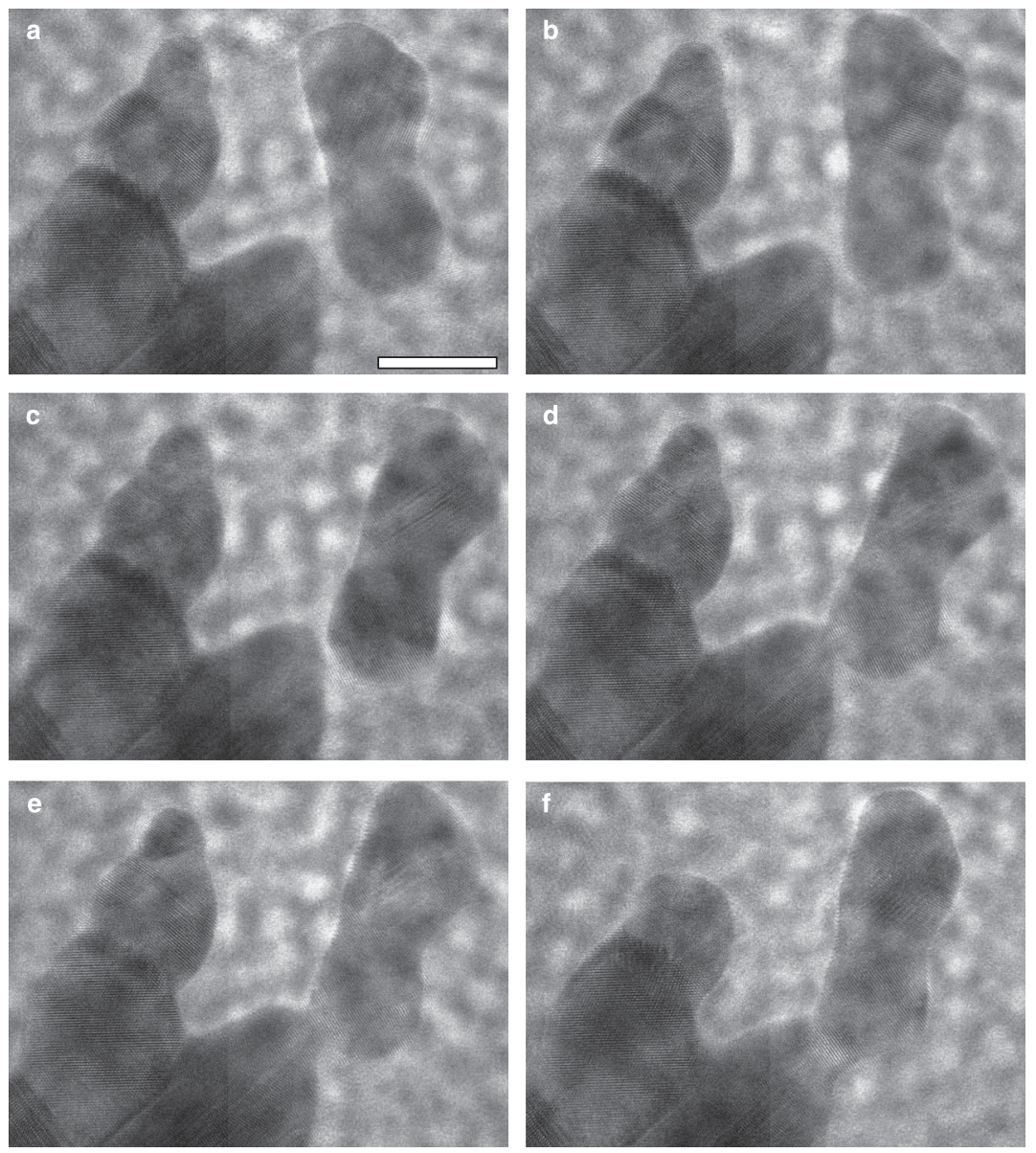

Figure 2. Growth of ferrihydrite (iron oxyhydroxide) via OA. a-f: Sequence of liquid cell transmission electron microscopy (TEM) images showing a dumbbell-shaped ferryhidrite particle formed during an earlier aggregation event, attaching to a larger crystal formed from many such events. As the dumbbell-shaped particle approaches the larger crystal (a-b), it feels the attractive force that drives OA and undergoes a significant clockwise rotation (b-d) before jumping to contact (c-d). Immediately following attachment, there are a number of lattice defects in the boundary region (d-e), but these quickly translate to the surface and are expelled, causing a counter-clockwise rotation of the particle about the new interface (f). Times in seconds: (a) 0, (b) 2.4, (c) 5.6, (d) 6.6, (e) 7.4, and (f) 32.2. Scale bar is 10 nm (also see Supplementary Movie 2). 
as $\alpha$, the barrier becomes (De Yoreo \& Vekilov, 2003; De Yoreo et al., in press)

$$
\begin{gathered}
\Delta g_{\mathrm{c}}=B \frac{\alpha^{3}}{\sigma^{2}}, \\
r_{\mathrm{c}}=\frac{F \omega \alpha}{k T \sigma},
\end{gathered}
$$

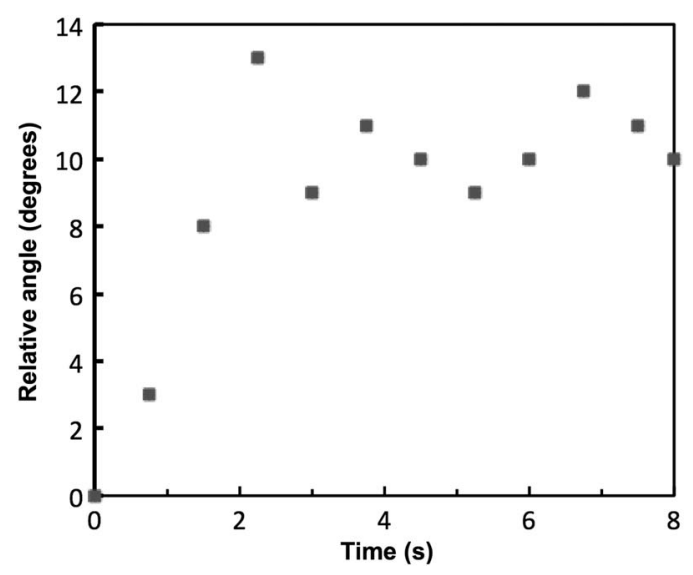

Figure 3. Dependence of relative orientation versus time following attachment of dumbbell-shaped ferryhidrite particle shown in Figure 2. The particle rotates counter clockwise at a rate of $87 \mathrm{mrad} / \mathrm{s}$ before reaching an equilibrium position.
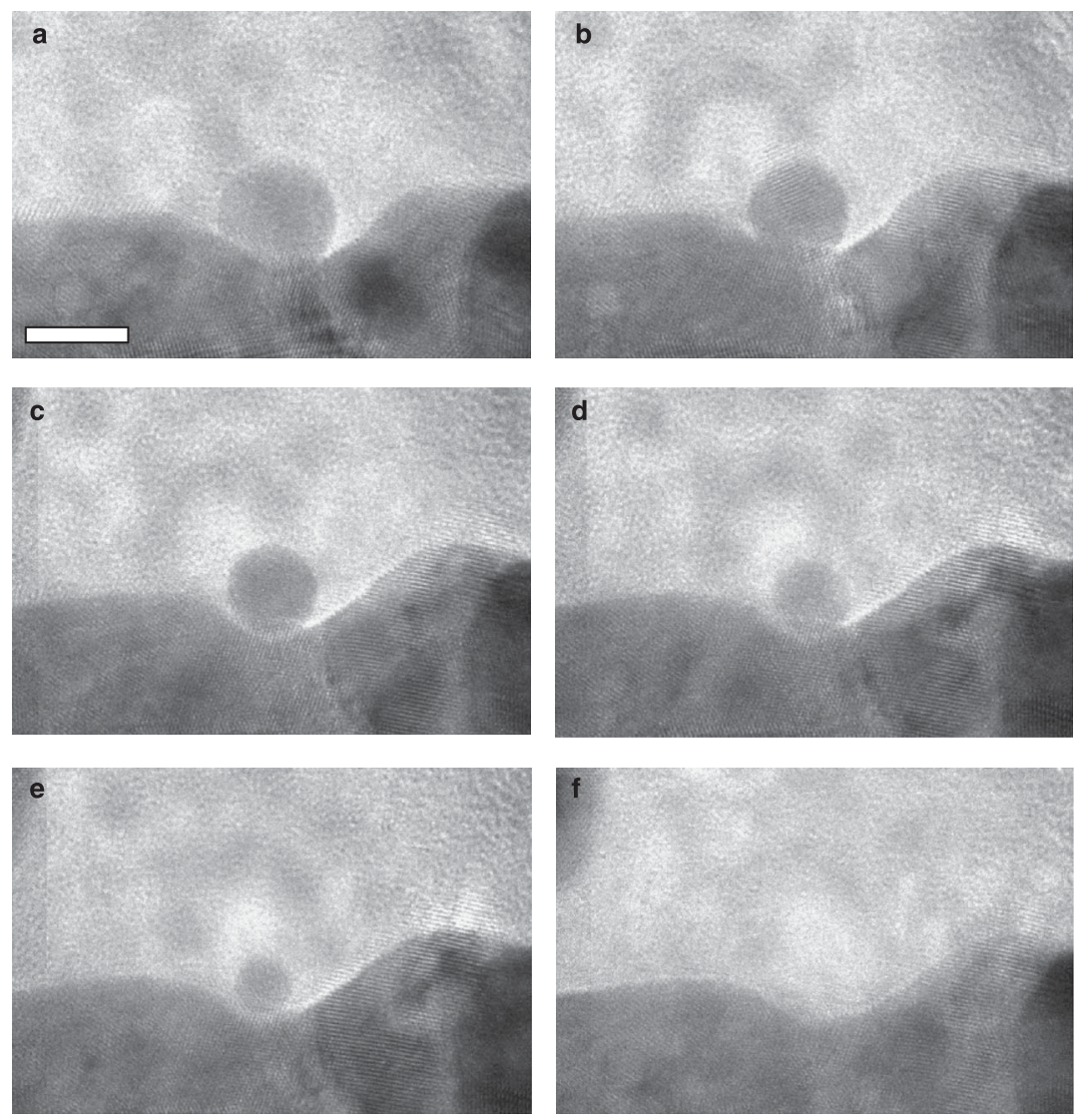

Figure 4. Ostwald ripening of ferrihydrite particles. a-f: Sequence of liquid cell transmission electron microscopy (TEM) images showing the dissolution of a small ferrihydrite particle with positive curvature near a large ferrihydrite surface with negative curvature. Times in seconds: (a) 0 , (b) 4.6, (c) 7.6, (d) 10.2, (e) 12.6, and (f) 14.6. Scale bar is $5 \mathrm{~nm}$. 
co-aligned prior to or during the attachment process so that the lattices of the contacting surfaces match. The result is that aggregation events create branched structures with interfaces that are either defect-free or delineated by twin planes. The sequence of images in Figure 2 was chosen because it illustrates the unique dynamic information provided by liquid cell TEM. The sequence shows an oblong particle presumably formed during an earlier OA event drifting by a larger branched particle formed through numerous aggregation events. As the lower left corner of the smaller particle passes near the larger mass with a relative orientation that is close to alignment, it experiences the attractive force that drives OA in this system (Li et al., 2012). This force exerts a torque on the particle rotating it clockwise into co-alignment and causing the final jump-to-contact. However, even after the initial attachment, line defects can be seen in the interface region and their elimination, most easily seen in Supplementary Movie 2, leads to a large readjustment of the alignment marked by a visible counterclockwise rotation. The end result of these events is to create a highly branched single crystal that could not form through the classical terrace-ledge-kink model of growth.

\section{Supplementary Movie 2}

Supplementary Movie 2 can be found online. Please visit journals.cambridge.org/jid_MAM.

Li et al. (2012) used measured values of rotational and translational accelerations during jump-to-contact to calculate the magnitude of the interaction potential in the ferrihydrite system. Assuming the underlying source of $\mathrm{OA}$ is Coulombic, as suggested by simulations (Zhang \& Banfield, 2012), they found that approximately one net unit charge on each particle would be required to create the estimated attractive force.

The torque $\tau$ that must be applied through relaxation of the interface in order to rotate the particle in Figure 2 through the observed post-attachment rotation angle $\theta$ can also be estimated from these experiments. Figure 3 shows the dependence of the relative angle on time. During the first $2 \mathrm{~s}$, the particle rotates counterclockwise through an angle of $10^{\circ}$ in $2 \mathrm{~s}$ giving a rate $\omega=87 \mathrm{mrad} / \mathrm{s}$. Because the dependence of angle on time is linear over this angle, the angular velocity is a constant, thus the net torque is zero. This means the torque due to relaxation of the interface is approximately equal to the resistive torque $\tau_{\mathrm{r}}$ due to rotation in the viscous medium. Following Li et al. (2012) we take $\tau_{\mathrm{r}}=8 \pi \eta r^{3} \omega$ where $r$ is the distance to the center of mass from the contact $(11 \mathrm{~nm})$ and $\eta$ is the viscosity, which is $5.8 \mathrm{E} 6 \mathrm{~g} / \mathrm{cm} \mathrm{s}$ for this system. The total energy of relaxation $U$ required to cause this rotation can then be estimated from $U=\tau_{\mathrm{r}} \bullet \theta=3.0 \mathrm{E}-12 \mathrm{erg}$. (If instead we calculate the energy needed to move an ellipsoid against the Stokes force through the distance $r \theta$, the estimated value of $U$ becomes $1.9 \mathrm{E}-12 \mathrm{erg}$, showing that the calculation is insensitive to the detailed geometry assumed.) One can get an order of magnitude
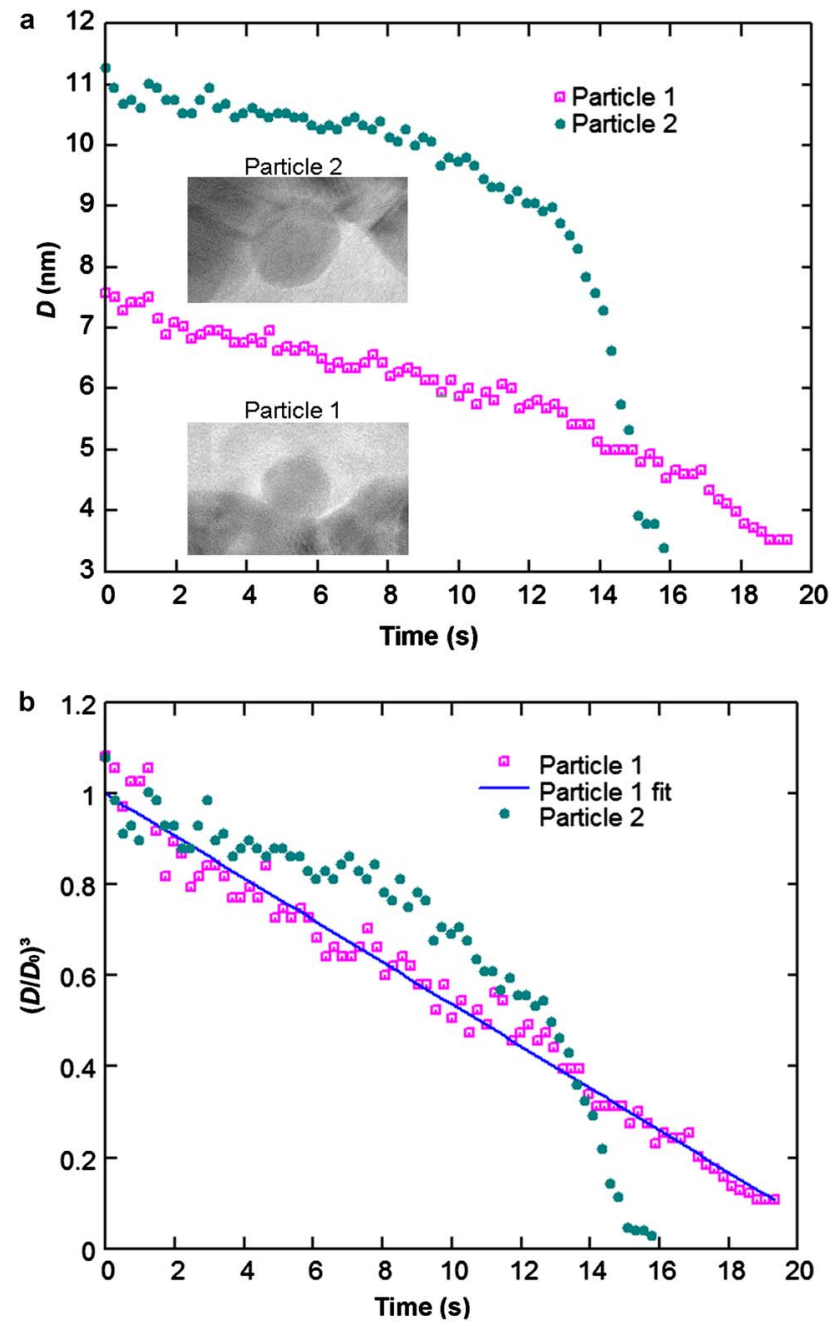

Figure 5. a: Decrease in diameter with time for an individual particle near a concave surface of a much larger particle. (Particle 1 is the same one shown in Figure 4. b: Plot of $\left(D / D_{0}\right)^{3}$ versus time for the two particles shown in (a).

estimate of the internal strain $\varepsilon$ this energy corresponds to from $\mathrm{U} \sim(1 / 2) \mathrm{VE} \varepsilon^{2}$ where $V$ is the volume of deformation and $E$ is the elastic modulus, which is of order $10-100 \mathrm{GPa}$ for inorganic solids. Taking $E=50 \mathrm{GPa}$, a radius of $\sim 5 \mathrm{~nm}$ at the interface and a deformation region of $\sim 5 \mathrm{~nm}$ in thickness (from Fig. 2), the strain is estimated to be $\sim 0.01$ or about $1 \%$.

Because the interaction of the particles often brings a small particle near a large particle, if the local curvature of the two particles differs significantly the process of integration can involve Ostwald-type ripening instead of aggregation. Figure 4 shows an example for the ferrihydrite system. A small particle with high positive curvature approaches a large ferrihydrite surface with negative curvature. Before an attachment event can occur, the small particle dissolves and is incorporated into the larger particle.

The dependence of particle size on time during the ripening process for the particle shown in Figure 4, as well as one other not shown here, is given in Figure 5. Although the two particles appear in similar local particle-particle 

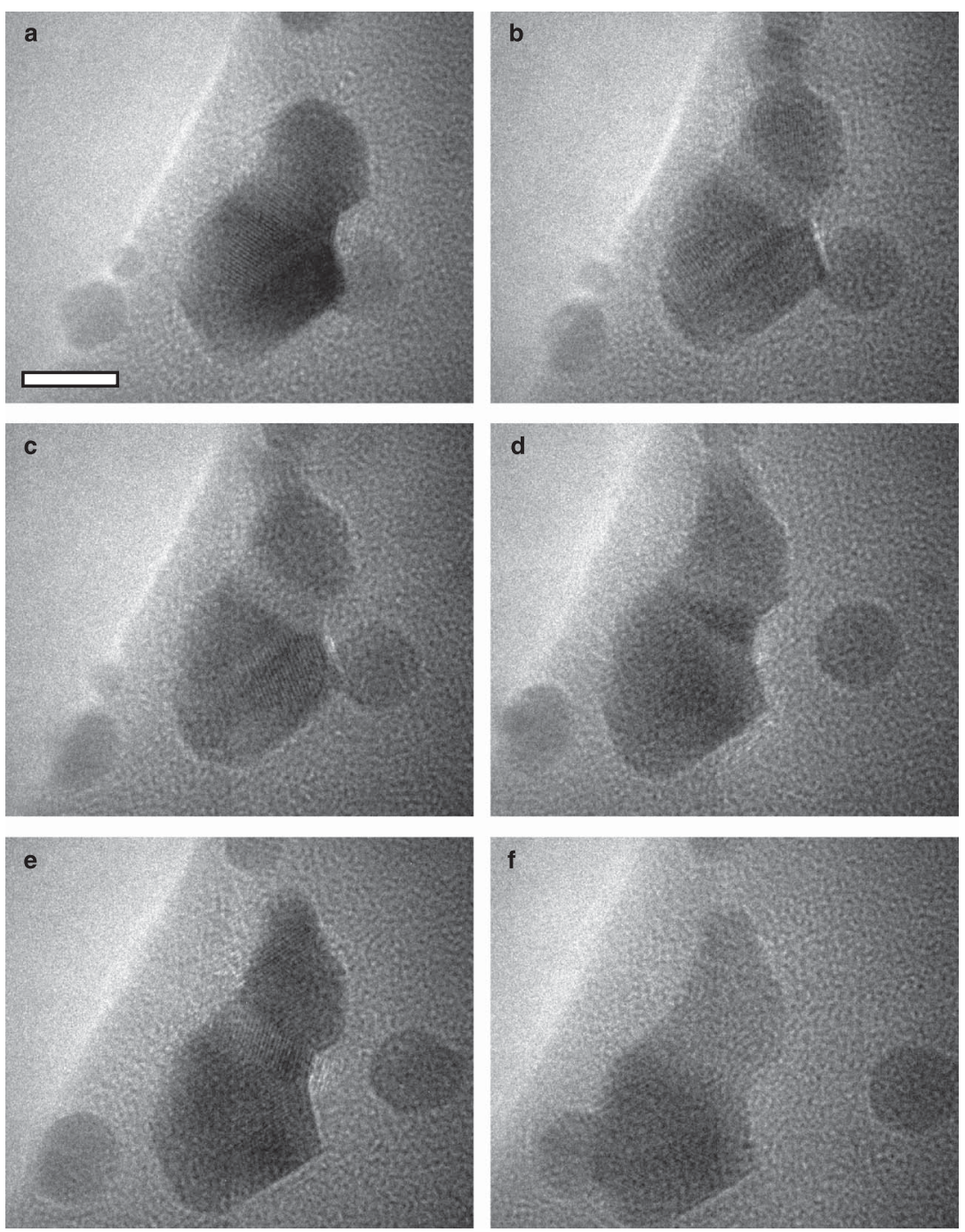

Figure 6. Growth of $\mathrm{CaCO}_{3}$ by particle aggregation. a-f: Sequence of liquid cell transmission electron microscopy (TEM) images showing small spherical $\mathrm{CaCO}_{3}$ particles with no apparent lattice structure interacting with and attaching to either one another or to a larger composite crystal. Times in seconds: (a) 0, (b) 0.8, (c) 1.3, (d) 3.3, (e) 4.5, and (f) 6.5. Scale bar is $5 \mathrm{~nm}$ (also see Supplementary Movie 3).

interaction environments, the dissolution kinetics are quite different. For particle 1, the fit to the third power law in Figure $5 b$ shows that its dissolution can be described well by Ostwald ripening controlled by the volume diffusion of ionic species in a solution (Joesten, 1991). On the other hand, the data for particle 2 cannot be described by any power law, suggesting factors other than size, such as the relative orientations of the dissolving and growing particles or the local environment (e.g., interface curvature), play a role in the dissolution and re-precipitation rate. The accelerated dissolution rate of this particle at $>\sim 12 \mathrm{~s}$ may also reflect the rapid increase in Coulombic interactions at close proximity as the effect of surface charge screening diminishes (Zhang \& Banfield, 2013).

Observations in the calcium carbonate system suggest a very different aggregation process than in the ferrihydrite system. Here, particle fusion is also observed, but the primary particles, which are of order $5 \mathrm{~nm}$ or less and spherical, appear to be amorphous (Figure 6 and Supplementary Movie 3). This conclusion is consistent with molecular dynamics simulations (Quigley et al., 2011; Raiteri \& Gale, 2011), which found that amorphous calcium carbonate should be the stable phase in the nm-range, despite the fact that all macroscopic crystalline phases of $\mathrm{CaCO}_{3}$ have much lower solubility (i.e., higher stability). These primary particles interact with and periodically attach to a larger particle that was created through prior aggregation events and is crystalline, as is evident from the faceted shape, the presence of lattice fringes, and the constantly changing scattering contrast. After attachment, lattice fringes can be seen in the smaller particles as well, indicating that growth in this system does not occur through OA, but rather via attachment of amorphous particles that then crystalize using the parent crystal as a template. Interestingly, during one experiment in which many well-formed crystals ranging in size from about 10 to $50 \mathrm{~nm}$ interacted over a period of several minutes (Supplementary Movie 4), 

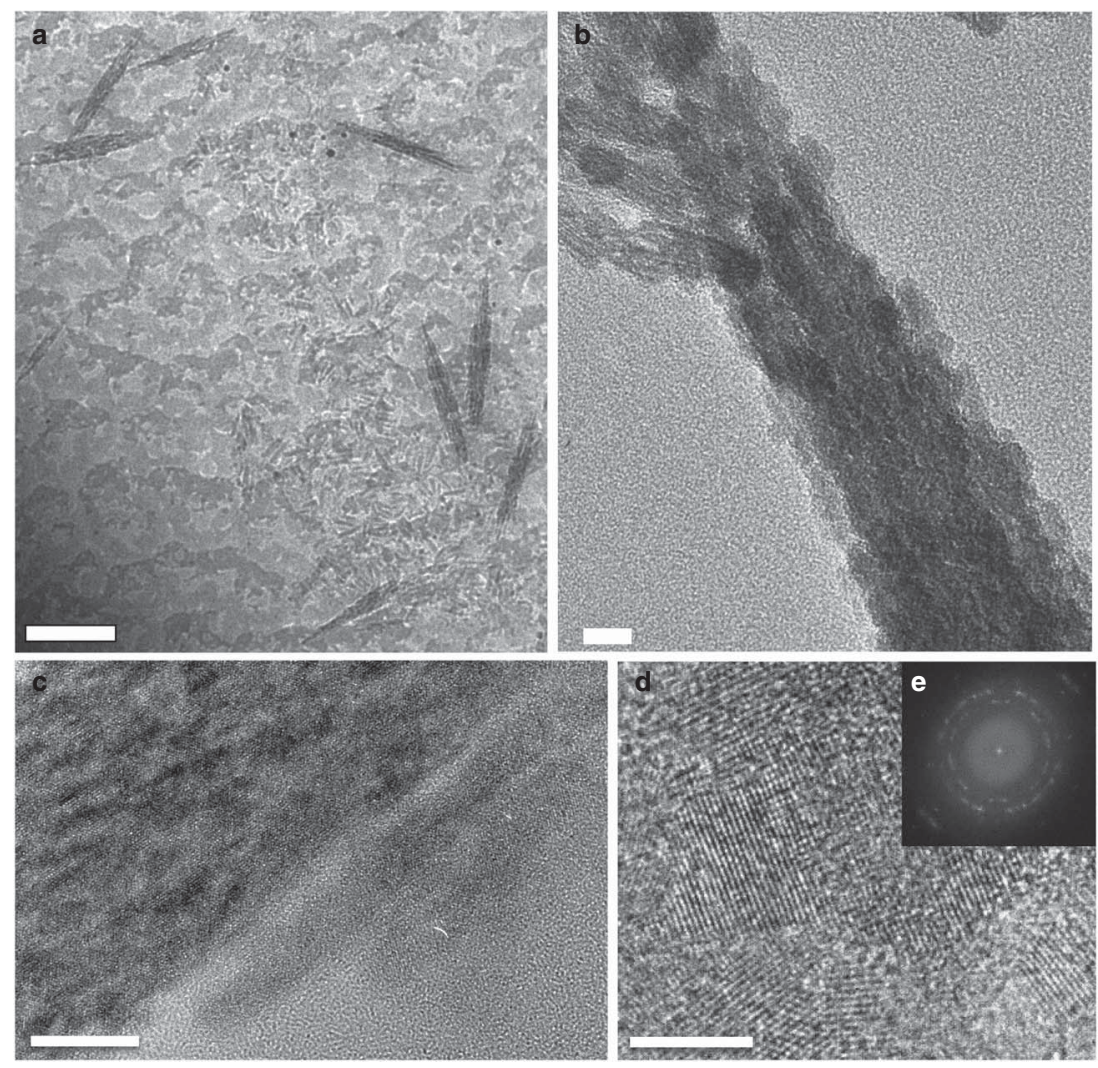

Figure 7. Growth of hematite $\left(\alpha-\mathrm{Fe}_{2} \mathrm{O}_{3}\right)$ spindles through aggregation of akaganeite nanorods $(\beta$-FeOOH). a: Liquid cell transmission electron microscopy (TEM) showing complete spindles, partial spindles, and nanorods. b: Ex situ image from same experiment showing assembly of the nanorods into a spindle. $\mathbf{c}$, $\mathbf{d}$ : High resolution images indicating that the akaganeite nanorods attach to the hematite spindles (c), but in this early stage the resulting hematite crystals are composed of randomly oriented domains $(\mathbf{d}, \mathbf{e})$. After an extended period of hydrothermal treatment, the hematite spindles become single crystal and exhibit a single well-defined diffraction pattern (Supplementary Fig. 1). Scale bars: (a) $200 \mathrm{~nm}$, (b) $10 \mathrm{~nm}$, (c) $10 \mathrm{~nm}$, (d) $5 \mathrm{~nm}$.

attachment events were not observed, suggesting that true OA in this system may be a rare event.

\section{Supplementary Movies 3 and 4}

Supplementary Movies 3 and 4 can be found online. Please visit journals.cambridge.org/jid_MAM.

The third style of aggregation-based growth is illustrated by the akaganeite-hematite system. Akaganeite (an iron oxyhydride) forms nanorods in solution that may aggregate to eventually form spindle-shaped single crystals of hematite (an iron oxide) (Ocana et al., 1995; Frandsen et al., 2014). In the akaganeite-hematite system, phase transition and growth appear interlinked, as in the calcium carbonate system, but in this system both primary and secondary particles are crystalline. Frandsen et al. (2014) used ex situ and cryo-TEM to develop a model for the formation of these spindles based on OA of the akaganeite nanorods followed by transformation to hematite due to a size-dependent inversion of the iron oxide phase stability; after which spindle growth happens by aggregation of akaganeite onto hematite. In this study, liquid cell TEM shows hematite spindles in the solution with akaganeite nanorods and significant network formation between particles (Fig. 7a). Although the rods tend to exhibit at least partial co-alignment, the images here show that the nanorods initially aggregate with a high degree of disorder compared with that observed during ferrihydrite aggregation (Fig. 2) (Li et al., 2012). Disorder is further evident in early hematite spindles based on diffraction contrast (Fig. 7c), lattice images (Fig. 7d), and Fourier transform analysis (Fig. 7d, inset), but this disorder is eliminated over time through internal reorganization to produce highly perfect single crystal hematite spindles (Supplementary Fig. 1). Thus this system is intermediate between the case of ferrihydrite, where attachment is highly orientation dependent (as observed from lattice plane alignment), and that of calcium carbonate where the precursor is amorphous and hence overall particle orientation plays no role. Nonetheless, in all three cases the final crystals are highly perfect single crystals.

\section{Supplementary Figure 1}

Supplementary Figure 1 can be found online. Please visit journals.cambridge.org/jid_MAM. 


\section{DISCUSSION}

\section{Other Studies of Nanoparticle Growth}

Fluid cell TEM has been used to investigate nucleation and growth phenomena in a growing number of other nanoparticle systems in recent years, including Pt (Zheng et al., 2009; Yuk et al., 2012), PbS (Evans et al., 2011), Ag (Woehl et al., 2012), Bi (Xin \& Zheng, 2012), Pd (Parent et al., 2012), $\mathrm{Pt}_{3} \mathrm{Fe}$ (Liao et al., 2012), Pd on Au seeds (Jungjohann et al., 2013), and $\mathrm{ZnO}$ (Liu et al., 2013). Although many of these investigations have included the nucleation stage, discussion of nucleation is either largely absent or restricted to looking at induction times and/or dependence of nucleation density on beam dosage. Growth, rather than nucleation, has largely been analyzed and discussed. Both investigations of Pt nanoparticle growth found two distinct regimes that occurred concomitantly. Slow growth by atomic addition was punctuated by rapid growth periods following particle fusion events. This result is consistent with the atomicresolution observations on ferrihydrite shown in Figure 2, showing that, following attachment, particles grow rapidly in response to the negative curvature created at the point of
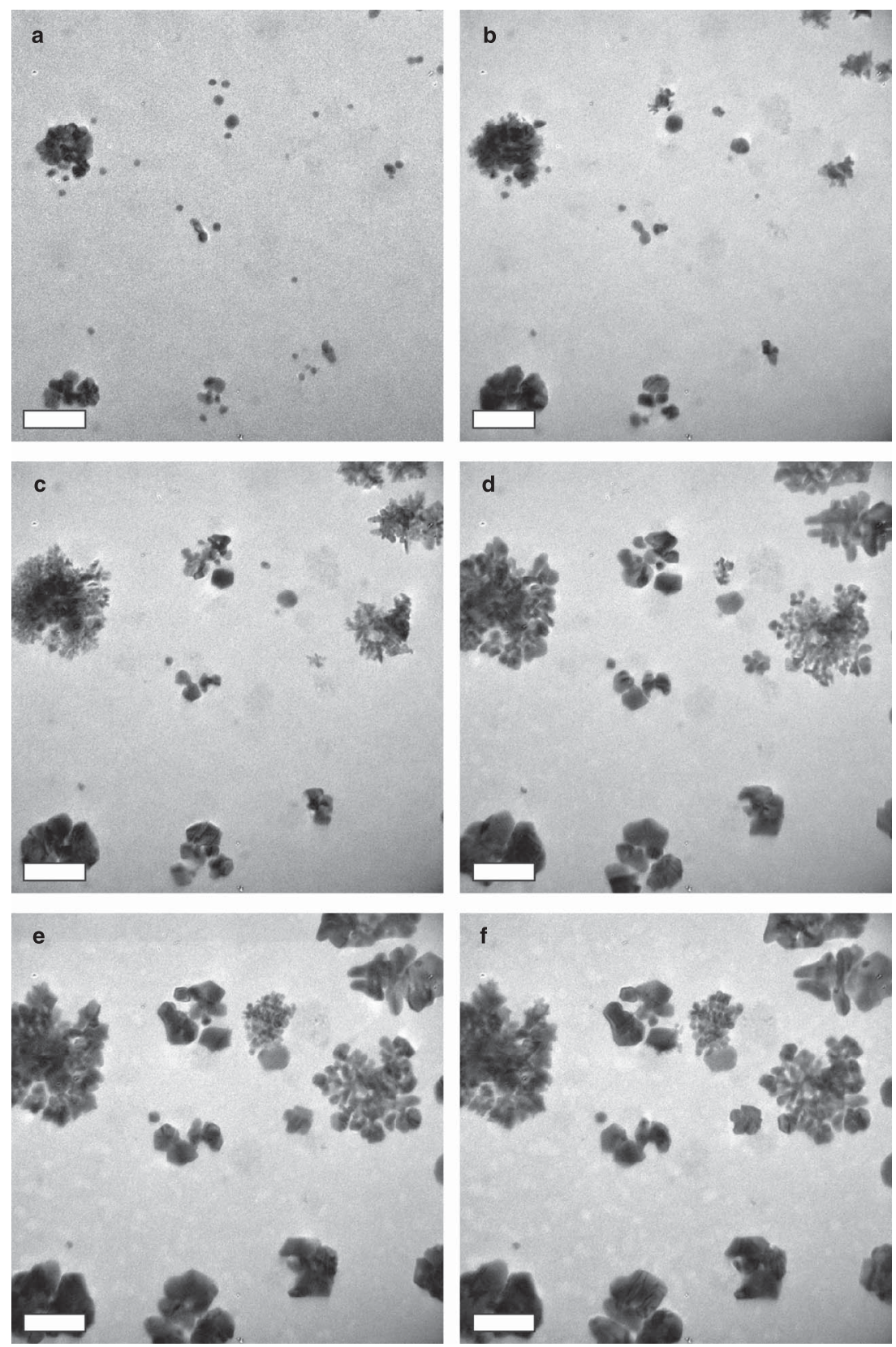

Figure 8. Onset of dendritic Au nanoparticle growth due to the electron beam. a-f: Sequence of liquid cell transmission electron microscopy (TEM) images showing appearance of dendritic growth front followed by dendrite collapse and particle coalescence. Times in seconds: (a) 0.0, (b) 15.4, (c) 28.8, (d) 52.4, (e) 77.0, and (f) 84.6. Scale bar is $100 \mathrm{~nm}$ (also see Supplementary Movie 5). 
attachment. Growth through atomic addition and fusion events were also seen under at least some conditions of the remainder of the systems listed above. Ostwald ripening was reported for $\mathrm{ZnO}$ growth and as an active process in the size fluctuations of $\mathrm{Bi}$, that were similar to those reported here for ferrihydrite and shown in Figure 4. Pd on Au exhibited, under certain conditions, dendritic growth with continued exposure to the electron beam, similar to our observations of Au shown in Figure 8.

\section{Electron Beam Effects}

Despite the power of liquid cell TEM in providing direct evidence for specific mechanisms of crystallization from solution as well as dynamic information that can help to constrain important energetic parameters, the method has significant limitations. First, in order to get high resolution, the thickness of the liquid layer must be of order $100 \mathrm{~nm}$ or less. Unfortunately, particles in this geometry tend to interact with the surfaces of the liquid cell, dramatically reducing their mobility. Second, the small volume of liquid available for a reaction severely limits the extent to which a growth process can be followed.

These two issues are minor compared with the problems posed by beam effects. In nearly all experiments we have performed, the beam either triggers the reaction or impacts its rate. For example, in the case of the experiments on gold nanoparticle nucleation, the solutions are stable for extended periods of time absent exposure to the beam; and in the experiments with iron oxyhydroxides, the initial solution contains nanorods of akaganeite. However, in the electron microscope these dissolve and are replaced by new particles of ferrihydrite. In previous work where we reported the nucleation of $\mathrm{CaCO}_{3}$ on a gold electrode deposited on the cell window, again, nucleation did not occur until the cell was exposed to the beam.

A dramatic example of beam effects is given in Figure 8 and Supplementary Movie 5, which shows the growth of Au nanoparticles. As growth proceeds under continuous exposure, the particles suddenly begin to exhibit rapid growth with a dendritic morphology. Eventually, these dendrites, which have high curvature, collapse to form more compact, faceted crystals. These eventually aggregate and coalesce with one another. However, the entire process is instigated by the beam.

\section{Supplementary Movie 5}

Supplementary Movie 5 can be found online. Please visit journals.cambridge.org/jid_MAM.

\section{CONCLUSIONS}

The results presented here suggest that liquid cell TEM will become a powerful tool for addressing outstanding scientific questions that have arisen in recent years concerning the mechanisms underlying nucleation and growth of crystals from electrolyte solutions. Results on nucleation of gold nanoparticles show that the process exhibits the characteristic feature of classical nucleation, while the data on crystal growth by nanoparticle aggregation demonstrate that no single pathway or controlling mechanism is at work. While some systems may exhibit true OA, others appear to involve aggregation of precursor phases that may be initially misaligned or even amorphous and thus require a postaggregation crystallization or recrystallization step. Due to the importance of nucleation and growth processes in geochemical, biological, and synthetic systems, the information obtained using liquid cell TEM has the potential to impact a wide range of fields. However, the full impact awaits development of well-tested low dose imaging techniques as well as liquid cells that have a reproducible thickness and are instrumented to provide full knowledge of solution conditions including $\mathrm{pH}$, temperature, and ion concentrations.

\section{ACKNOWLEDGEMENTS}

Transmission electron microscopy was performed at the Molecular Foundry and the National Center for Electron Microscopy, Lawrence Berkeley National Laboratory, with support from the US Department of Energy Office of Science, Office of Basic Energy Sciences under Contract DE-AC02-05CH11231. Research on iron oxide was performed with support from US Department of Energy Office of Science, Office of Basic Energy Sciences. Research on calcium carbonate was performed with support from the National Science Foundation under grant DMR-1312697. M. H. Nielsen acknowledges Government support under and awarded by DoD, Air Force Office of Scientific Research, National Defense Science and Engineering Graduate (NDSEG) Fellowship, 32 CFR 168a. J. Seto acknowledges financial support from the Foundation Pierre-Gilles de Gennes in Paris, France. C. Frandsen acknowledges support from The Danish Council for Independent Research. H. Zhang and J. F. Banfield acknowledge support from the National Science Foundation (Grant no. CHE-1213835) and US Department of Energy (Contract no. DE-AC02-05CH11231).

\section{REFERENCES}

Banfield, J.F., Welch, S.A., Zhang, H.Z., Ebert, T.T. \& Penn, R.L. (2000). Aggregation-based crystal growth and microstructure development in natural iron oxyhydroxide biomineralization products. Science 289(5480), 751-754.

Baumgartner, J., Dey, A., Bomans, P.H.H., Le Coadou, C., Fratzl, P., SommerdijK, N. \& Faivre, D. (2013). Nucleation and growth of magnetite from solution. Nat Mater 12(4), 310-314.

Bewernitz, M.A., Gebauer, D., Long, J., Cölfen, H. \& Gower, L.B. (2012). A metastable liquid precursor phase of calcium carbonate and its interactions with polyaspartate. Faraday Discuss 159, 291-312.

Burton, W.K., Cabrera, N. \& Frank, F.C. (1951). The growth of crystals and the equilibrium structure of their surfaces. Phil Trans R Soc A 243(866), 299-358. 
Chen, Q., Smith, J.M., Park, J., Kim, K., HO, D., Rasool, H.I., ZetTl, A. \& Alivisatos, A.P. (2013). 3D motion of DNA-Au nanoconjugates in graphene liquid cell electron microscopy Nano Lett 13, 4556-4561.

Cho, K.S., Talapin, D.V., Gaschler, W. \& Murray, C.B. (2005). Designing $\mathrm{PbSe}$ nanowires and nanorings through oriented attachment of nanoparticles. J Am Chem Soc 127(19), 7140-7147.

Cölfen, H. \& Antonietti, M. (2005). Mesocrystals: Inorganic superstructures made by highly parallel crystallization and controlled alignment. Angew Chem-Int Edit 44(35), 5576-5591.

Cölfen, H. \& Antonietti, M. (2008). Mesocrystals and NonClassical Crystallization. San Francisco, USA: John Wiley and Sons.

De Yoreo, J.J. (2013). Nucleation: More than one pathway. Nat Mater 12, 284-285.

De Yoreo, J.J. \& VeKilov, P.G. (2003). Principles of crystal nucleation and growth. In Biomineralization, Dove, P.M., DeYoreo, J.J. \& Weiner, S. (Eds.), pp. 57-93. Washington: Mineralogical Soc America.

de Yoreo, J.J., Waychunas, G.A., Jun, Y.-S. \& Fernandez-Martinez, A. (In press). In situ investigations of carbonate nucleation on mineral and organic surfaces. In Geochemistry of Geological $\mathrm{CO}_{2}$ Sequestration, Bourg, I., Steefel, C. \& Navrotsky, A. (Eds.), pp. 229-257. Washington: Mineralogical Society America.

Dey, A., Bomans, P.H.H., Muller, F.A., Will, J., Frederik, P.M., DE With, G. \& Sommerdij, N. (2010). The role of prenucleation clusters in surface-induced calcium phosphate crystallization. Nat Mater 9(12), 1010-1014.

Evans, J.E., JungJohann, K.L., Browning, N.D. \& Arslan, I. (2011). Controlled growth of nanoparticles from solution with in situ liquid transmission electron microscopy. Nano Lett 11, 2809-2813.

FaAtz, M., Grohn, F. \& Wegner, G. (2004). Amorphous calcium carbonate: Synthesis and potential intermediate in biomineralization. Adv Mater 16(12), 996-1000.

Frandsen, C., Legg, B.A., Comolli, L.R., Zhang, H., Gilbert, B., Johnson, E. \& BANField, J.F. (2014). Aggregation-induced growth and transformation of $\beta-\mathrm{FeOOH}$ nanorods to micron-sized $\alpha$-Fe2O3 spindles. Cryst Eng Comm 16, 1451-1458.

Gebauer, D. \& Cölfen, H. (2011). Prenucleation clusters and nonclassical nucleation. Nano Today 6(6), 564-584.

Gebauer, D., Volkel, A. \& Cölfen, H. (2008). Stable prenucleation calcium carbonate clusters. Science 322(5909), 1819-1822.

GiBBS, J.W. (1876). On the equilibrium of heterogeneous substances. Trans Connect Acad Sci 3, 108-248.

GibBs, J.W. (1878). On the equilibrium of heterogeneous substances. Trans Connect Acad Sci 16, 343-524.

Habraken, W., Tao, J.H., Brylka, L.J., Friedrich, H., Bertinetti, L., Schenk, A.S., Verch, A., Dmitrovic, V., Bomans, P.H.H., Frederik, P.M., Laven, J., van der Schoot, P., Aichmayer, B., De With, G., Deyoreo, J.J. \& Sommerdij, N. (2013). Ion-association complexes unite classical and non-classical theories for the biomimetic nucleation of calcium phosphate. Nat Commun, 4, Article no. 1507.

Hackney, S.A., Biancaniello, F.S., Yoon, D.N. \& Handwerker, C.A. (1986). Observations on crystal defects associated with diffusion induced grain boundary migration in Cu-Zn. Scripta Metallurgica 20(6), 937-942.

Joesten, R.L. (1991). Kinetics of coarsening and diffusion-controlled material growth. In Contact Metamorphism, Reviews in Mineralogy vol. 26, pp. 507-582 (Eds.), pp. 507-582. Washington, DC: Mineralogy Society of America.
Jungjohann, K.L., Bliznakov, S., Sutter, P.W., Stach, E.A. \& Sutter, E.A. (2013). In situ liquid cell electron microscopy of the solution growth of Au - Pd core - shell nanostructures. Nano Lett 13, 2964-2970.

Kashchiev, D. (1999). Nucleation: Basic Theory with Applications. Oxford, UK: Butterworths-Heinemann.

Killian, C.E., Metzler, R.A., Gong, Y.U.T., Olson, I.C., Aizenberg, J., Politi, Y., WILT, F.H., Scholl, A., Young, A., Doran, A., KunZ, M., Tamura, N., Coppersmith, S.N. \& Gilbert, P. (2009). Mechanism of calcite co-orientation in the sea urchin tooth. J Am Chem Soc 131(51), 18404-18409.

Li, D.S., Nielsen, M.H., Lee, J.R.I., Frandsen, C., Banfield, J.F. \& DE YoReO, J.J. (2012). Direction-specific interactions control crystal growth by oriented attachment. Science 336(6084), 1014-1018.

LiaO, H.G., Cui, L.K., Whitelam, S. \& Zheng, H.M. (2012). Real-time imaging of $\mathrm{Pt}_{3} \mathrm{Fe}$ nanorod growth in solution. Science 336(6084), 1011-1014.

LiU, Y., TaI, K. \& Dillon, S.J. (2013). Growth kinetics and morphological evolution of $\mathrm{ZnO}$ precipitated solution. Chem Mater 25, 2927-2933.

Mann, S. (2001). Biomineralization: Principles and Concepts in Bioinorganic Materials Chemistry. Oxford, UK: Oxford University Press.

Nielsen, M.H., Lee, J.R.I., Hu, Q.N., Han, T.Y.J. \& De Yoreo, J.J. (2012). Structural evolution, formation pathways and energetic controls during template-directed nucleation of $\mathrm{CaCO} 3$. Faraday Discuss 159, 105-121.

Ocana, M., Morales, M.P. \& Serna, C.J. (1995). The growthmechanism of alpha-fe2o3 ellipsoidal particles in solution. J Colloid Interface Sci 171(1), 85-91.

Parent, L.R., Robinson, D.B., Woehl, T.J., Ristenpart, W.D., Evans, J.E., Browning, N.D. \& Arslan, I. (2012). Direct in situ observation of nanoparticle synthesis in a liquid crystal surfactant template. ACS Nano 6(4), 3589-3596.

Passchier, C.W. \& Trouw, R.A.J. (1998). Microtectonics. Wurzburg. Springer.

PenN, R.L. \& BANFIELD, J.F. (1998a). Imperfect oriented attachment: dislocation generation in defect-free nanocrystals. Science 281, 969-971.

PENN, R.L. \& BANFIELD, J.F. (1998b). Oriented attachment and growth, twinning, polytypism, and formation of metastable phases: Insights from nanocrystalline TiO2. Mineralogist 83, 1077-1082.

Penn, R.L., Zhu, C., Xu, H. \& Veblen, D. (2001). Iron oxide coatings on sand grains from the Atlantic coastal plain: High-resolution transmission electron microscopy characterization. Geology 29, 843-846.

Politi, Y., Arad, T., Klein, E., Weiner, S. \& Addadi, L. (2004). Sea urchin spine calcite forms via a transient amorphous calcium carbonate phase. Science 306(5699), 1161-1164.

Pouget, E.M., Bomans, P.H.H., Goos, J.A.C.M., Frederik, P.M., DE With, G. \& Sommerdij, N.A.J.M. (2009). The initial stages of template-controlled caco3 formation revealed by cryo-TEM. Science 323(5920), 1455-1458.

Quigley, D., Freeman, C.L., Harding, J.H. \& Rodger, P.M. (2011). Sampling the structure of calcium carbonate nanoparticles with metadynamics. J Chem Phys 134(4), 044703.

Radisic, A., Ross, F.M. \& SEArson, P.C. (2006a). In situ study of the growth kinetics of individual island electrodeposition of copper. J Phys Chem B 110(15), 7862-7868.

Radisic, A., Vereecken, P.M., Hannon, J.B., Searson, P.C. \& Ross, F.M. (2006b). Quantifying electrochemical nucleation and growth of nanoscale clusters using real-time kinetic data. Nano Letters 6(2), 238-242. 
Raiteri, P. \& Gale, J.D. (2011). Water is the key to nonclassical nucleation of amorphous calcium carbonate. J Am Chem Soc 132(49), 17623-17634.

van Driessche, A.E.S., Benning, L.G., Rodriguez-Blanco, J.D., Ossorio, M., Bots, P. \& Garcia-Ruiz, J.M. (2012). The role and implications of bassanite as a stable precursor phase to gypsum precipitation. Science 336(6077), 69-72.

Wallace, A.F., Hedges, L.O., Fernandez-Martinez, A., Raiteri, P., Gale, J.D., Waychunas, G.A., Whitelam, S., Banfield, J.F. \& DE YoREO, J.J. (2013). Microscopic evidence for liquid-liquid separation in supersaturated $\mathrm{CaCO} 3$ solutions. Science 341 (6148), 885-889.

Williamson, M.J., Tromp, R.M., Vereecken, P.M., Hull, R. \& Ross, F.M. (2003). Dynamic microscopy of nanoscale cluster growth at the solid-liquid interface. Nat Mater 2(8), 532-536.

Woenl, T.J., Evans, J.E., Arslan, I., RistenPart, W.D. \& Browning, N.D. (2012). Direct in situ determination of the mechanisms controlling nanoparticle nucleation and growth. ACS Nano 6(10), 8599-8610.

Wolf, S.E., Leiterer, J., Kappl, M., Emmerling, F. \& Tremel, W. (2008). Early homogenous amorphous precursor stages of calcium carbonate and subsequent crystal growth in levitated droplets. J Am Chem Soc 130(37), 12342-12347.
XIN, H.L. \& ZHENG, H. (2012). In situ observation of oscillatory growth of bismuth nanoparticles. Nano Lett 12, 1470-1474.

Xu, An-Wu, Antonietti, Markus, Yu, Shu-Hong, Cölfen, H. (2008). Polymer-mediated mineralization and self-similar mesoscaleorganized calcium carbonate with unusual superstructures. $A d v$ Mater 20(7), 1333.

Yadong, Y. \& Alivisatos, P. (2005). Colloidal nanocrystal synthesis and the organic-inorganic interface. Nature 437(7059), 664-670.

Yuk, J.M., PArk, J., Ercius, P., Kim, K., Hellebusch, D.J., Crommie, M.F., LeE, J.Y., ZetTL, A. \& Alivisatos, A.P. (2012). High-resolution EM of colloidal nanocrystal growth using graphene liquid cells. Science 336, 61-64.

ZHANG, H.Z. \& BANFIELD, J.F. (2012). Energy calculations predict nanoparticle attachment orientations and asymmetric crystal formation. J Phys Chem Lett 3(19), 2882-2886.

Zhang, H. \& BANFIEld, J.F. (2013). Interatomic Coulombic interactions as the driving force for oriented attachment. Cryst Eng Comm, 16, 1568-1578.

Zhang, J., HuAnG, F. \& Lin, Z. (2010). Progress of nanocrystalline growth kinetics based on oriented attachment. Nanoscale 2(1), 18-34.

Zheng, H., Smith, R.K., Jun, Y.-W., Kisielowski, C., Dahmen, U. \& Alivisatos, A.P. (2009). Observation of single colloidal platinum nanocrystal growth trajectories. Science 324, 1309-1312. 